\title{
Changes in the open field behavior of female golden hamsters'
}

\section{DENNIS JOWAISAS, ${ }^{2}$ University of Florida, Gainesville, Fla. 32601}

Six female hamsters (Mesocricetus auratus) were given three 15-min tests, spaced 40 min apart, in an open field containing novel objects. The Ss' behavior was sampled at 6-sec intervals and assigned to one of nine categories. The frequency of scratching and biting the floor and walls of the field and freezing increased over the three tests while the amount of nonobject sniffing decreased. Although the frequency of grooming did not change, the latency to the first recorded instance of grooming reliably decreased across test sessions.

The increasing interest in the general activity and behavior of animals, both in their home areas and in novel situations, has been directed primarily towards the laboratory rat. A notable exception has been the work of Glickman and his associates (Glickman \& Hartz, 1964; Glickman \& Sroges, 1965; Glickman \& Schiff, 1967), but no detailed descriptions of hamster open-field behavior appear to have been published. The following report deals with the changes in the spontaneous behavior of female hamsters during successive tests in an open-field situation.

\section{SUBJECTS}

Six female golden hamsters (Mesocricetus auratus), 100 to 110 days old, served as Ss. A number of animals were obtained from a commercial supplier at 90 days of age and maintained in groups of 10 per cage under typical laboratory conditions. For six days prior to the experiment, the six randomly selected animals used as $S$ s were separated from the groups and housed in individual cages. Food and water were available ad lib at all times in the home cage. A 12-h light-dark cycle (lights off at 9 PM) was maintained automatically in the colony room. The temperature was regulated at $72 \mathrm{deg} \pm 4 \mathrm{deg}$.

\section{APPARATUS}

The open field was constructed of plywood walls and a hardware cloth floor $(1 / 4-i n$. mesh). The walls were $1 \mathrm{ft}$ high and painted a flat black; they enclosed an area $2 \times 2 \mathrm{ft}$. The field rested on a hardboard-topped table. Three novel objects, a $35-\mathrm{mm}$ film can, a rubber water bottle stopper and a threaded pipe fitting, were fastened to the wire-mesh floor near the center of the field.

A constant $76 \mathrm{~dB}$ of white noise was present during all testing. A shaded incandescent lamp provided $4 \mathrm{ft}-\mathrm{c}$ of illumination at the center of the field floor.

Standard programming equipment delivered a tone every $6 \mathrm{sec}$ to a pair of headphones located in the testing room. The equipment also flashed a dim red light which was fixed to the outside of one wall of the field, 6 in. below the top edge. A cover allowed the light to be clearly seen by the $O$ seated in darkness, $2 \mathrm{ft}$ from the open field, but no light could be detected from inside the field itself. All programming apparatus was located outside the testing room.

\section{PROCEDURE}

The Ss were tested in groups of three on two successive nights between the hours of $10 \mathrm{PM}$ and $1 \mathrm{AM}$. On the first night all Ss were tested for signs of estrus by placing a castrated male hamster, supported by hormone injections, in the S's cage for approximately $2 \mathrm{~min}$. Any evidence of lordosis disqualified an $S$ from testing on that night. Three of the Ss showed signs of estrus and were assigned to the group tested on the following night. A period of $1 / 2 \mathrm{~h}$ elapsed between the test for estrus and the start of the first open-field test.

One $S$ at a time was taken from the colony room to the testing room in her own cage. The cage was covered and put in the testing room while the score sheet was made ready and headphones were checked (about $2 \mathrm{~min}$ ). The $\mathrm{S}$ was then placed by hand into the field at the same time as a signal was heard in the headphones, and at every signal thereafter the behavior of the $S$ was noted and recorded. At the end of $15 \mathrm{~min}$ the $\mathrm{S}$ was removed from the field, placed in its cage and returned to the colony room, and the procedure was repeated with the next $S$. This process was repeated until each $S$ had received three tests; the intertest interval was $40 \mathrm{~min}$. Food and water were available in the home cages between test sessions.

The following behavior categories, suggested by pilot work, were used: FREEZING, $S$ immobile; SNIFFING, vigorous movements of the nose and vibrissae; GROOMING, scratching, biting and licking of the body and limbs as well as "washing" movements; MARKING, rubbing the scent gland areas against the field; FIELD DIRECTED BEHAVIOR, scratching and biting the floor and walls of the field; WALKING, four-legged locomotion; REARING, raising upon the hind limbs, body extended, sometimes with one forelimb resting on the field wall; OBJECT DIRECTED BEHAVIOR, sniffing and biting the objects in the field; and MISCELLANEOUS, sitting, lying, stretching, and yawning.

\section{RESULTS}

Since a number of the behaviors recorded were mutually exclusive and were therefore interdependent, separate analyses of variance with Tests as a repeated measure were applied to all categories except miscellaneous. The response frequency in each category, expressed as a percentage of the total number of recorded responses, is shown in Table 1.

The analyses of variance revealed reliable changes across Tests in field-directed responses $[\mathrm{F}(2,10)=14.79, \mathrm{p}<.01]$, sniffing $[F(2,10)=9.62, \quad p<.01]$, and freezing $[F(2,10)=14.69, p<.01]$. The Newman-Keuls range test showed that field-directed behavior increased in Tests 2 and 3 , as did the instances of freezing $(p<.01)$. In neither case were the differences between Tests 2 and 3 significant. Sniffing decreased in Tests 2 and 3 when compared to Test $1(p<.01)$ but showed no reliable change from Test 2 to Test 3 .

Examination of the records suggested that the latency to the first recorded instance of certain behaviors changed over the course of testing. Single analyses of variance with repeated measures were performed on the latency scores for sniffing, walking, and grooming. Only the latter category resulted in a significant $F$ ratio $[F(2,10)=4.17, p<.05]$. Grooming responses were emitted earlier in Test 3 than in Test 1 according to the Newman-Keuls test $(\mathrm{p}<.05)$, while the onset of grooming in Test 2 did not differ from that in Tests 1 or 3.

Table 1

Response Frequency as a Percentage of Total Number of Responses.

\begin{tabular}{lrrrr} 
& \multicolumn{3}{c}{ Test } & Total \\
Freezing & 1 & 2 & 3 & \\
Sniffing & 1.2 & 3.3 & 2.8 & 2.4 \\
Rearing & 24.0 & 16.2 & 14.6 & 18.3 \\
Walking & 11.3 & 8.9 & 9.7 & 10.0 \\
Marking & 12.2 & 10.9 & 8.0 & 10.4 \\
Field Directed & 1.3 & 0.7 & 1.4 & 1.1 \\
Object Directed & 24.9 & 41.2 & 46.1 & 37.4 \\
Grooming & 5.1 & 1.8 & 1.8 & 2.9 \\
Miscellaneous & 18.3 & 15.2 & 14.8 & 16.1 \\
\hline
\end{tabular}


The average latency was $169 \mathrm{sec}$ for Test 1 and $34 \mathrm{sec}$ for Test 3.

A priori, one would expect that the dependent probabilities between various classes of behavior change as an animal habituates to a situation. That is, given that some behavior, $X$, occurred at $t \mathrm{sec}$, what is the probability that Behavior $\mathrm{Y}$ (or $Z$, etc.) will be recorded at $t+6 \mathrm{sec}$. By counting the number of times the recorded behavior changes from one sampling period to the next within a test session, a rough assessment of the "stereotypy" of responding during the 15-min test is obtained (Bindra \& Spinner, 1958). The mean number of changes for Tests 1,2 , and 3 were $91.8,82.5$, and 75.0, respectively; these differences were not reliable $[F(2,10)=3.37, \mathrm{p}>.05]$.

\section{DISCUSSION}

The comparison of the results of the present study with those of studies of novelty responses in the rat is complicated by the fact that the complexity of the test situation with respect to the home area is a potent determinant of response frequency. Woods \& Davidson (1964) have convincingly demonstrated that novelty or change per se has less effect on exploration (sniffing) than does increased complexity of the test condition.

The paucity of object-directed responses in the hamsters (2.9\% of all responses) was unexpected and may mean that the complexity of the open field in comparison to the home cage was not great enough to elicit much object oriented responding. Under such conditions changes could hardly occur. Alternatively, the high frequency of field directed behavior was clearly incompatible with exploration of objects in the center of the field.

The Bindra \& Spinner (1958) findings on within-test habituation for sniffing responses in rats applies to the between-test results for hamsters, as does the rise in the frequency of freezing. The changes observed in grooming and walking in the rat were not found to occur in the hamster. It is possible that the handling of the hamsters before each test and the intertest interval account for these discrepancies. Handling might serve to partially reinstate the response probabilities extant at the time of the initial test. The nonsignificance of change in grooming frequency coupled with the reliable effect of Tests on grooming latency would fit this hypothesis.

Increased freezing during the latter periods of testing seems to be a reliable finding in the work on rats. Woods (1962) noticed that the O-generated noises were increasingly likely to result in freezing responses as the test session drew to a close and hypothesized that as the $S$ habituated to the test situation these random stimuli came to be the most novel stimuli present. Great care was taken in the present experiment to minimize such random stimuli and create a constant background of auditory stimulation with white noise. No sources of visual stimulation could be identified as the cause of the significant increases of freezing in the hamsters. Casual attempts to visually distract the Ss at the conclusion of testing failed unless the $\mathbf{O}$ moved closer to the field and made gross bodily movements. With visual and auditory stimuli minimized, olfactory stimuli would appear to be sufficient to cause increased freezing under Woods' hypothesis.

A description of the predominant behavior classed as field-directed responses is in order since at least $90 \%$ of field-directed behavior seen in Test 3 was stereotyped "scrabbling." The Ss would rear on their hind legs with their bellies facing the wall and vigorously scratch the wall with their extended forepaws. Soon after the initial rearing one hind leg would also be used to claw at the wall. The eventual result was a loss of balance causing the $S$ s to slowly slide laterally and downward along the wall until reaching the floor whereupon the Ss would rear up and repeat the sequence. This pattern of successive rearing and falling of ten carried an $S$ along the perimeter of two or more walls before being interrupted by some other behavior. Pearl (1963) has noted that in a bar-press situation a large number of "adventitious" responses accrue to hamsters due to biting the bar and climbing-like behavior which appears to be the "scrabbling" observed in the present study. The high probability of the scrabbling response suggests that it may represent a species-typical behavior which is of adaptive value to a burrow dwelling animal.

\section{REFERENCES}

BINDRA, D., \& SPINNER, N. Response to different degrees of novelty: The incidence of various activities. Journal of the Experimental Analysis of Behavior, 1958, 1, 341-350:

GLICKMAN, S. 'E., \& HARTZ, K. E. Exploratory behavior in several species of rodents. Journal of Comparative \& Physiological Psychology, 1964, 58, 101-104.

GLICKMAN, S. E., \& SCHIFF, B. B. A biological theory of reinforcement. Psychological Review, 1967, 74, 81-109.

GLICKMAN, S. E., \& SROGES, R. W. Curiosity in zoo animals. Behaviour, 1965, 26, 151-158.

PEARL, J. Avoidance learning in rodents: A comparative study. Psychological Reports, 1963, 12, 139-145.

WOODS, P. J. Behavior in a novel situation influenced by the immediately preceeding environment. Journal of the Experimental Analysis of Behavior, 1962, 5, 185-190.

WOODS, P. J., \& DAVIDSON, E. H. The behavioral effects of changes in environmental complexity. Canadian Journal of Psychology, 1964, 18, 23-27.

\section{NOTES}

1. I wish to thank Dr. B. N. Bunnell for the use of the animals and Dr. D. A. Dewsbury for providing the materials for this study.

2. This work was done while the author was a fellow of the Center for Neurobiological Sciences.

\section{(Continued from page 125)}

intensive exploration within maze arms and not lack of exploration. For the present explanation to hold true, therefore, the implication is that the typical pattern of exploration in rats is one of intensive locomotion between arms.

\section{REFERENCES}

LESTER, D. Exploratory behavior of dominant and submissive rats. Psychonomic Science, 1967a, 9, 285-286.

LESTER, D. Exploratory behavior in peripherally blinded rats. Psy chonomic Science, 1967b, 8, 7-8.

LESTER, D. Effects of fear upon exploratory behavior. Psychonomic Science, $1967 \mathrm{c}, 9,117-118$

LESTER, D. Effects of olfactory stimuli on Y-maze exploration of rats.
Psy chonomic Science, 1968a, 12,97.

LESTER, D. Comment on Sheldon. Psychonomic Science, 1968b, in press.

MONTGOMERY, K. C. The relation between fear induced by novel stimulation and exploratory drive. Joumal of Comparative \& Phy siological Psychology, 1955, 4, 254-260.

SHELDON, M. H. Exploratory behavior: The inadequacy of activity measures. Psychonomic Science, 1968, 11, 38.

$$
\text { NOTES }
$$

1. This research was supported by Research Grant MH 14404-01 from the National Institute of Mental Health.

2. Lester, D., \& Cheses, K. T. The reliability of exploratory measures 2: Y-maze exploration. Unpublished manuscript, Wellesley College, 1968. 